\title{
A NOTATION FOR THE GEOMETRY OF THE SPHERE.
}

HoWARD F. HART.

The writer in perfecting the proof of the theorem, "A spherical triangle equals a lune whose angle is half the spherical excess of the triangle," so that it would not seem so clumsy, discovered the notation given below. He further found that it not only simplified the proof of this proposition, but also that of others in the geometry of the sphere as well.

In this notation the spherical triangle of angles $A, B$, and $C$ is denoted by $\mathrm{TA}_{\mathrm{A}}, \mathbf{B}, \mathrm{C}$; the spherical polygon of angles $\mathrm{A}_{1}, \mathrm{~A}_{2} \ldots \ldots \mathrm{A}_{n}$ by $P_{A_{1}}, A_{2} \ldots \ldots A_{n}$; the lune of angle $A$ by $L_{A}$; etc.

Theu we have, e. $g$. :

(1) $\mathrm{LA} \pm \mathrm{LB}_{\mathrm{B}}=\mathrm{L}_{\mathrm{A}} \pm \mathrm{B}$

(2),$\frac{1}{n} \mathrm{LA}_{\mathrm{A}}=\mathrm{LA}_{\mathrm{A}} / n$

(3) $\frac{L_{A}}{L_{B}}=\frac{A}{B}$

(4) $\mathrm{L}_{360^{\circ}}=4 \pi \mathrm{R}^{3}$

(5) $\mathrm{TA}_{\mathrm{A}} \mathrm{B}, \mathrm{C}=\frac{\mathrm{L} \mathrm{A}+\mathrm{B}+\mathrm{C}-180^{\circ}}{2}$ (which is the theorem quoted above)

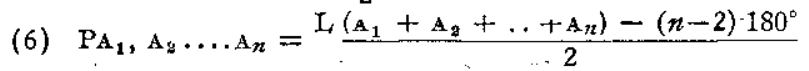

etc.

It will be observed that the notation is operative, which is probably the cause of its simplifying power and of its success as a class. room device.

High School, Montclair, N.J.

\section{NOTE ON "A DIRECT DFMONSTRATION."}

\author{
WM. A. LuBY.
}

"A Direct Demonstration" in Scrool Science and Mathematics for May is incorrect. The error creeps in at the point where it is proved that $\mathrm{AH}=\mathrm{AG}$. It follows then that $\mathrm{G}$ and $\mathrm{H}$ are the same point, and that $\mathrm{DX}$ intersects $\mathrm{EZ}$ in that point. Call the intersection $G$. and if follows that $\mathrm{E}$ is either on $\mathrm{DG}$, above it or below it. To assume that $\mathrm{E}$ is on DG is to assume that the original theorem is true. Two other assumptions remain, giving the two possibilities illustrated in the figures below, In each of these figures angles IEG and IFG are not alternate interior angles. The conclusion that $\mathrm{DX}$ is parallel to $\mathrm{EZ}$ is therefore false.

Central High School, Kansas City, Mo. 